\title{
FLOW STUDY AND WETTING EFFICIENCY OF A PERFORATED-PLATE TRAY DISTRIBUTOR IN A TRICKLE BED REACTOR
}

\author{
D. Ramajo ${ }^{a}$, S. Marquez Damian ${ }^{a}$, M. Raviculé ${ }^{b}$, M. Monsalvo ${ }^{b}$, M. Storti $^{a}$ \\ and N. Nigro ${ }^{a}$ \\ ${ }^{a}$ International Center for Computational Methods in Engineering (CIMEC) \\ INTEC-UNL-CONICET, Güemes 3450, Santa Fe, Argentina, dramajo@santafe- \\ conicet.gov.ar \\ ${ }^{\mathrm{b}}$ Centro de Tecnología Argentina (CTA), YPF, Baradero s/nro. 1925, Ensenada, \\ Argentina,_mravicules@ypf.com
}

Keywords: tray efficiency, trickle bed reactor, petrochemical, CFD.

\begin{abstract}
Trickle bed reactors (TBRs) are massively employed in petrochemical and chemical plants. In general these reactors have one or more beds filled up with catalyst particles. Efficient catalyst utilization relies on a good liquid charge distribution across the catalyst beds. However, normally the distribution is not perfect and some parts of the beds will get less liquid reactants while others will get more than the average. In zones where there is a maldistribution of reactants the reaction will progress in undesirable way leading to deactivation of the catalyst and towards low conversions. Bad tray efficiency due to non-uniform liquid distribution will result in low reactor efficiency and shorten the catalyst's cycle time.

The TBR analyzed here is a hydrogenation one that processes $\mathrm{C}_{4}$ (liquid) and hydrogen (gas) to produce butene 1 (also named $\alpha$ butylene). The two-phase charge is introduced through the upper side of the TBR and the liquid phase accumulates on the tray to a certain level swamping the perforated-plate tray. The liquid phase flows down through 68 small holes while the gas phase circulates through 7 gas chimneys. There is another ceramic-ball bed above the catalyst bed with the aim to obtain a better distribution of the charge.

In this work a computational fluid dynamics analysis (CFD) employing the Eulerian two-fluid model was carried out with the aim to understand the fluid
\end{abstract}


dynamics of the distribution process and to determine the wetting efficiency of the tray distributor under different operating conditions. The small tray holes were modeled by sinks (drains) and sources, firstly employing numerical and experimental models to obtain the flow rate versus liquid height response.

Because of the scarce liquid sloshing above the tray, little differences on the liquid discharge through the holes were found. Due to the low gas fraction of the charge the liquid flows only by gravity following an almost vertical trajectory from the holes to the ceramic ball bed. So, the extension of the wetted zone at the top of the ceramic ball bed is small. A suitable correlation to estimate liquid diffusion inside the ceramic-ball bed was employed, showing that the overall catalyst bed surface is wetted but significant differences on liquid fraction are found. Moreover, a possible additional cause of the low TBR efficiency could be the well known fouling vulnerability of this kind of tray distributors. In this sense, two simple geometric modifications were proposed to enhance tray performance; firstly reducing the amount of gas chimneys to only one, thus adding additional drip points, secondly replacing the holes by short risers in order to reduce the vulnerability to plugging.

\section{INTRODUCTION}

Fixed-bed reactors operating under trickle-flow conditions (TBRs) are massively employed in hydrotreating processes petroleum refineries, petrochemical plants and in many gas-liquid-solid reactions of the chemical industry. Since the introduction of fixed-bed hydroprocessing technology in the early 1950's significant improvements on catalyst efficiency have been done. But in the mid 1990's it becomes apparent that the design of hydroprocessing reactors had not advanced at the same pace as the development of hydroprocessing catalysts. As a result, licensors began to develop high performance reactor internals. Of course, technologies are licensed and scarce information about their behavior is available in open literature (Ranade, 2002).

There are three crucial issues affecting reactor efficiency; effective catalyst utilization, optimum gas/liquid distribution, and low radial temperature differences. It is well known that liquid flow maldistribution in TBRs is responsible for creating damaging hot spots, which are observed by thermocouple monitoring. A good design of the liquid distributor is one of the important factors to prevent liquid maldistribution in industrial scale reactors. However, even though uniform liquid distribution may be achieved at the distributor, significant bypassing (channeling) and/or segregation could occur due to the improper way in which catalyst and fines are packed (Wu and Dudukovic, 1995). For example, a $2.5 \%$ flow bypass in a single-bed reactor with a $2 \mathrm{wt} \%$ sulfur content feedstock would lead to a product containing at least 500 ppm of sulfur (Harter et al., 2001). 
The literature on liquid distribution is scanty as compared to that on other hydrodynamic parameters. Most of them focused on study the flow distribution within the catalyst bed (Lopes and Quinta-Ferreira, 2008; Gunjal et al., 2005; Kundu et al., 2001), and a few dealing with the distributors and trays efficiency (Maiti and Nigam, 2007; Harter et al., 2001). Finally, some of them study the effect of the distributor over the liquid behavior inside the catalyst bed (Atta et al., 2007).

Regarding perforated-plate trays, they are vulnerable to plugging by solid particles entering to the reactor, coke or corrosion products. Moreover, small tray unevenness caused during installation can also lie to loss of efficiency (Alvarez et al., 2007; Maiti et al., 2007).

Computational fluid dynamics (CFD) is beginning to be employed as a useful tool for helping developers to design more efficient liquid distributors (Harter et al., 2001).

Here the analyzed TBR is a multiphase (gas-liquid-solid) catalyst reactor employed to selective hydrogenation in which gas and liquid phases flow cocurrently downwards through a fixed bed of solid catalyst particles. In this work the focus is on the CFD analysis of the entry device of an industrial TBR. Investigation was focused to understand the two-phase fluid flow behavior and the tray wetting efficiency. Perforated-plate tray holes were modeled using sink (drain) and source points, and the effect of the ceramic-ball bed above the catalyst bed was estimated by an empirical equation. This methodology allowed the simulation of the overall entry device with relatively low computational resources.

\section{METHODOLOGY}

\subsection{TBR characteristics}

The TBR is a cylindrical reactor (diameter $=0.56 \mathrm{~m}$, total height $=6.5 \mathrm{~m}$ ) with only one catalyst bed of $\mathrm{Pd} / \mathrm{Al}_{2} \mathrm{O}_{3}$ (height $=4.7 \mathrm{~m}$ ), operating in plug flow regime. The inlet charge is a mixture of mainly $\mathrm{C}_{4}$ (liquid) and small amounts of hydrogen that is injected approximately $4 \mathrm{~m}$ upstream of the TBR (the volume fraction of each phase depend on the operating conditions). Charge is sprayed onto the perforated-plate tray distributor (diameter $=0.56 \mathrm{~m}$, thickness $=8 \mathrm{~mm}$ ) from a central inlet distributor flooding the tray. Fig. 1 shows the geometry of the entry device of the TBR, this being approximately $20 \%$ of the total reactor height. The inlet distributor is a short duct (diameter $=4$ inches) with 5 equidistant vertical slots (wide $=10 \mathrm{~mm}$, length $=100 \mathrm{~mm}$ ) and 15 holes (diameter $=10 \mathrm{~mm}$ ) on the bottom side. The perforated-plate of the tray consists of 7 gas chimneys (diameter $=37 \mathrm{~mm}$ ) and 68 holes (diameter $=10$ $\mathrm{mm}$ ) for liquid flow. Liquid swamps the tray to a certain level and flows 
through the holes by gravity. Below the tray and above the catalyst bed there is a ceramic-ball bed (ball diameter $=3 / 4$ inch, bed height $=150 \mathrm{~mm}$ ) to enhance liquid distribution. Fig. 2 shows the sketch of the perforated-plate tray. Holes are placed over a rhomboidal lattice while chimneys are radially distributed. In the figure the inlet duct is indicated with dashed lines.

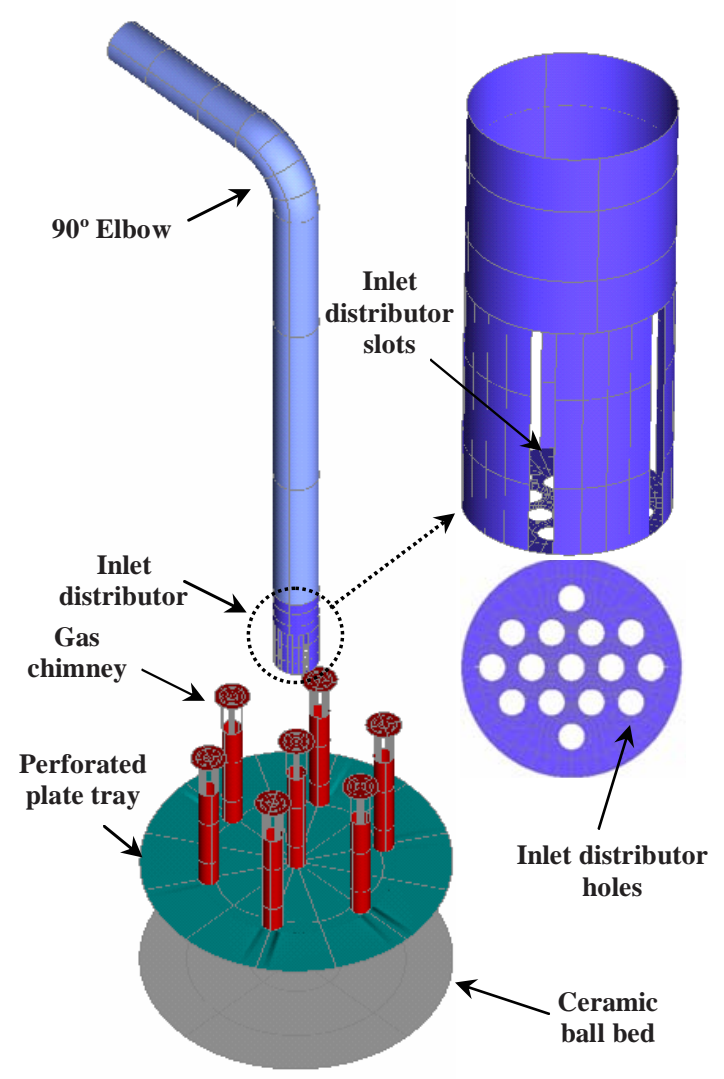

Figure 1. Geometry of the entry device and tray distributor 


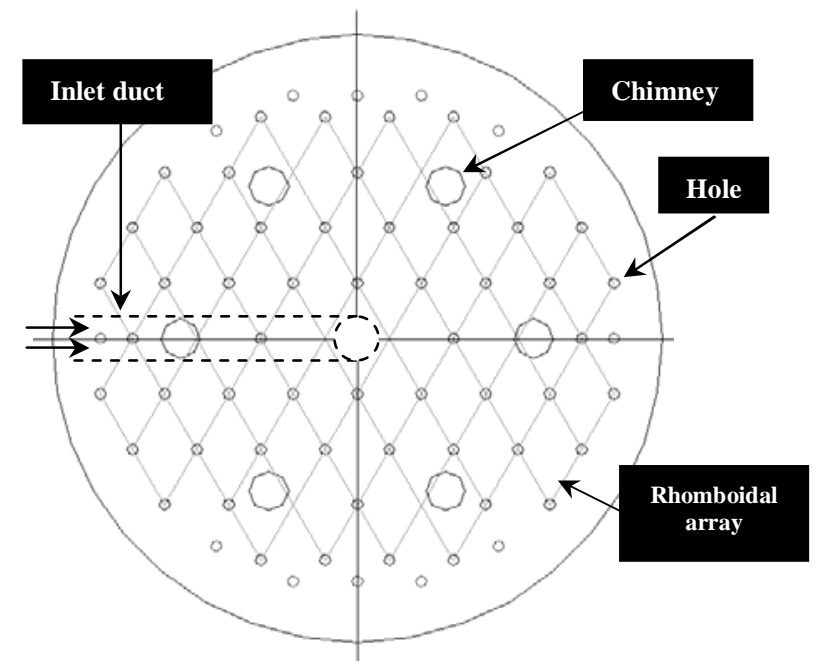

Figure 2. Sketch of the perforated-plate tray showing the 68 holes and the 7 chimneys

Operating conditions and fluid properties change in function of the catalyst aging and its progressive deactivation. Table 1 shows the data employed for simulation, corresponding to the beginning of catalyst's life; e.g. for aged catalyst both temperature and pressure are increased in order to hold conversion efficiency, that leading to negligible amounts of gas at the inlet.

Table 1. Operating conditions and fluid properties

\begin{tabular}{|l|c|}
\hline Temperature & $44.5^{\circ} \mathrm{C}$ \\
\hline Pressure Liquid phase \\
\hline \multicolumn{2}{|c|}{$11.3 \mathrm{~kg} / \mathrm{cm}^{2}$} \\
\hline Mass flow rate & $12447 \mathrm{~kg} / \mathrm{h}$ \\
\hline Density & $565.6 \mathrm{~kg} / \mathrm{m}^{3}$ \\
\hline Dynamic viscosity & $0.135 \mathrm{centipoise}$ \\
\hline Surface tension & $9.78 \mathrm{dyn} / \mathrm{cm}$ \\
\hline \multicolumn{2}{|c|}{ Gas phase } \\
\hline Mass flow rate & $8.3 \mathrm{~kg} / \mathrm{h}$ \\
\hline Density & $10.2 \mathrm{~kg} / \mathrm{m}^{3}$ \\
\hline Dynamic viscosity & $0.012 \mathrm{centipoise}$ \\
\hline
\end{tabular}

\subsection{Computational model}

The computational domain was meshed with 1.845.274 tetrahedral elements and 345.219 nodes. As it was mentioned, only the entry device (showed in Fig. 1) of the overall TBR was simulated while the ceramic-ball bed effect was modeled by an empirical expression. Fig. 3 shows the corresponding surface mesh. Note that the mesh was locally refined around the inlet distributor and gas chimneys. 


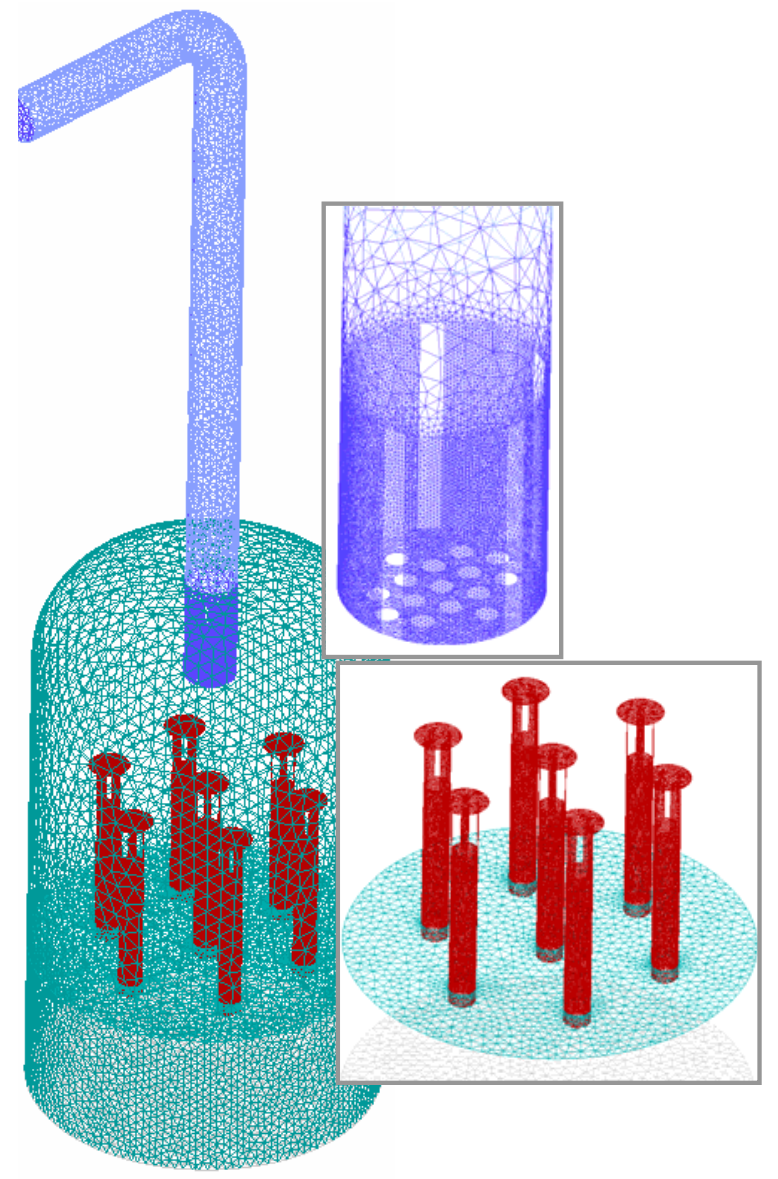

Figure 3. Surface mesh of the computational model

The unsteady multi-fluid formulation using the two-fluid model was employed for the simulation. As it is well known from theory (Drew and Passman, 1998), in this formulation single phase Navier-Stokes equations are modified according to some sort of regularization or average to model the small scales, introducing the volume fraction of each phase along with appropriate terms considering the mass, momentum and energy transferred through the interface among the phases. Since no reactions take place at the entry device of the TBR, the problem was modelled as isothermal and both phases were assumed as incompressible, because of the relatively low gas velocities. Continuity equation for $\alpha$ phase is: 


$$
\frac{\partial\left(\delta_{\alpha} \rho_{\alpha}\right)}{\partial t}+\nabla \bullet\left(\delta_{\alpha} \rho_{\alpha} \vec{U}_{\alpha}\right)=S_{\alpha}+\sum_{\beta \neq \alpha} \Gamma_{S, \alpha \beta} \text { and } \sum_{\alpha} \delta_{\alpha}=1
$$

where $\delta_{\alpha}$ is the volume fraction, $\rho_{\alpha}$ the density, $S_{\alpha}$ the mass sources or sinks, $\vec{U}_{\alpha}$ the velocity and $\Gamma_{S, \alpha \beta}$ the interfacial mass transfer. Note from Equation 1 that the summation of the volume fraction of all phases must be 1 , being a constrain condition. Regarding the momentum equation, it can be written as:

$$
\begin{aligned}
& \frac{\partial}{\partial t}\left(\delta_{\alpha} \rho_{\alpha} \vec{U}_{\alpha}\right)+\nabla \bullet\left(\delta_{\alpha}\left(\rho_{\alpha} \vec{U}_{\alpha} \otimes \vec{U}_{\alpha}\right)\right)= \\
& -\delta_{\alpha} \nabla P+\nabla \bullet \tau_{\alpha}+\delta_{\alpha} \varphi_{\alpha}+S_{M \alpha}+\sum_{\beta \neq \alpha} M_{\alpha \beta}+\sum_{\beta \neq \alpha} \Gamma_{M, \alpha \beta}
\end{aligned}
$$

where $P$ is the static pressure (shared for all phases), $\tau_{\alpha}$ is the shear stress tensor, $\varphi_{\alpha}$ is the external volumetric momentum source (potential force fields, i.e. gravity), $S_{M \alpha}$ are momentum sources and $M_{\alpha \beta}$ is the interface force caused by the presence of others phases, commonly divided between drag and nondrag forces (Drew and Passman, 1998; Mendez et al., 2005). Finally $\Gamma_{M \alpha \beta}$ are the net momentum quantities transferred at the interface between $\alpha$ and $\beta$ phases by phase change. In this work both $\Gamma_{S, \alpha \beta}$ in Equation 1 and $\Gamma_{M \alpha \beta}$ in Equation 2 were not taking into account while $S_{\alpha}$ and $S_{M \alpha}$ were employed to represent tray holes as sinks and sources of mass and momentum. Interaction between phases depends on the rheology characterization of phases. In this case, both of them were assumed as continuous fluids. Only drag forces were considered, taking a constant drag coefficient $C_{D}$ equal to 0.44 (turbulent regime). The interface drag force $D_{\alpha \beta}$ and the interface area $A_{\alpha \beta}$ in each control volume of the mesh was estimated by:

$$
D_{\alpha \beta}=C_{D} \rho_{\alpha \beta} A_{\alpha \beta}\left|U_{\beta}-U_{\alpha}\right|\left(U_{\beta}-U_{\alpha}\right) \text { and } A_{\alpha \beta}=\frac{\delta_{\alpha} \delta_{\beta}}{l_{\alpha \beta}}
$$

being $\rho_{\alpha \beta}$ the mixture density and $l_{\alpha \beta}$ a mixture length scale that was assumed equal to the average mesh-element size $(5 \mathrm{~mm})$. The standard two equation $k-\varepsilon$ model was employed to model turbulence and a standard logarithmic wall law was applied to represent the logarithmic flow velocity field near walls, to avoid a large mesh refinement. The $k-\varepsilon$ model has been extensively employed to simulate multiphase industrial systems due to its robustness and accuracy with relatively rough meshes (Ramajo et al., 2008). The transport equations for the turbulent variables $k$ and $\varepsilon$ are:

$$
\frac{\partial(\rho k)}{\partial t}+\frac{\partial\left(\rho U_{i} k\right)}{\partial x_{i}}=\frac{\partial}{\partial x_{i}}\left(\frac{\mu_{t}}{\sigma_{k}} \frac{\partial k}{\partial x_{i}}\right)+G-\rho \varepsilon
$$

and 
$\frac{\partial(\rho \varepsilon)}{\partial t}+\frac{\partial\left(\rho U_{i} e\right)}{\partial x_{i}}=\frac{\partial}{\partial x_{i}}\left(\frac{\mu_{t}}{\sigma_{\varepsilon}} \frac{\partial \varepsilon}{\partial x_{i}}\right)+\frac{\varepsilon}{k}\left(C_{1} G-C_{2} \rho \varepsilon\right)$

where $\mu_{t}$ is the turbulent viscosity that rise from the eddy viscosity model:

$\mu_{t}=\frac{C_{\mu} \rho k^{2}}{\varepsilon}$

and $C_{1}, C_{2}, \sigma_{k}, \sigma_{\varepsilon}$ and $C_{\mu}$ are model constants, being 1.44, 1.92, 1.0, 1.3 and 0.09 respectively. In Eq. (4) and (5), $G$ is a production term that is estimated based on the velocity gradients and the turbulent viscosity as:

$G=\frac{1}{2} \mu_{t}\left(\nabla \bar{U}+(\nabla \bar{U})^{T}\right)^{2}$

Regarding time integration, a first order backward Euler scheme was applied. Several time steps from $0.001 \mathrm{sec}$. to $0.01 \mathrm{sec}$. were considered, being 0.005 sec. the maximum time step that guarantee an average RMS convergence criterion for equation residuals less than $1 \times 10^{-6}$. The problem was solved using distributed computing facilities over several processors in a Beowulf cluster (Storti et al., 2002; Sonzogni et al., 2002).

The mass flow rate of both phases and the turbulence intensity $(5 \%)$ was set at inlet. The surface of the ceramic-ball bed was represented by an opening condition fixing a static pressure equal to the reactor operation pressure $(11.3$ $\mathrm{kg} / \mathrm{cm}^{2}$ ). With this boundary condition it was possible that both phases can leave the domain but only the gas phase can reenter to it. Finally, no slip boundary condition with logarithmic wall law taking null roughness was set at walls. Simulations were initialized with a liquid level over the tray that was estimated based on the following correlation for the discharge mass flow rate through a flat-plate hole:

$$
\dot{m}=C . A \cdot \sqrt{2 g \rho^{2}\left(H_{0}-\frac{\left(P-P_{0}\right)}{g \rho}\right)}
$$

where $A$ is the cross sectional area of the hole, $\rho$ is the liquid density, $H_{0}$ and $P_{0}$ are a reference height and pressure, $P$ is the pressure evaluated at each drain position over the tray, $g$ is the gravity and $C$ is a shape coefficient that mainly depend on the shape of the hole edges (sharp or rounded) and the ratio between the diameter and the thickness of the hole $(10 \mathrm{~mm} / 8 \mathrm{~mm}=1.25)$. Note that in Equation 8 only the fluid density is considered. Viscosity, surface tension or any other rheology parameters for the fluid are neglected. However, it must be noted that flows through holes of small diameter are mostly turbulent, so that the wall friction and the shape coefficients become nearly constant. 
Based on reported data (Dally et al., 1993; Perry et al., 1984) the coefficient $C$ ranges from 0.6 to 0.8 . However, it was not found the specific coefficient for the current hole geometry, so CFD and experimental tests were carried out to estimate it.

\subsection{Reduced tray models}

The diameter and thickness of the holes of the perforated plate are of $10 \mathrm{~mm}$ and $8 \mathrm{~mm}$ respectively, while the tray diameter is around $570 \mathrm{~mm}$. That involves significant scale differences added to the large amount of holes (68). Therefore, three reduced models considering only one gas chimney and 12 tray holes were assessed to find a suitable option to model the holes. The first model (named model A) considers a non-thickness perforated-plate tray, the second one (named model B) considers a perforated-plate tray with the real thickness $(8 \mathrm{~mm})$ and the third one (named model C) considers a blind-plate tray, representing the holes as local mass and momentum sinks and sources above and bellow the tray, respectively. For these reduced models the fluid properties were the same as in the industrial TBR, being the mass flow rates of the liquid and the gas phases proportional to the amount of holes and chimneys, respectively. Fig. 4 shows the models mentioned above.

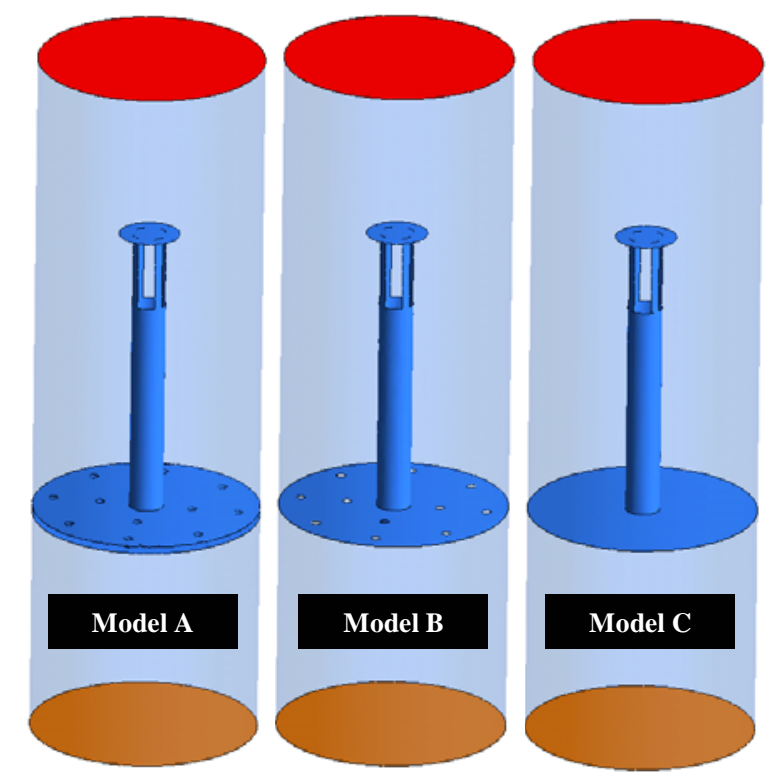

Figure 4. Reduced tray models

Table 2 displays the mesh sizes of the three reduced models. Note that the mesh size of model $\mathrm{C}$ is around a half of model A. Moreover, a better mesh quality was observed for model $\mathrm{C}$ due to the absence of the small holes. For model $\mathrm{B}$ 
two meshes were considered, the second one (model $\left.\mathrm{B}_{2}\right)$ considering a more refined mesh around the holes, that motivated by the unphysical results obtained with model $\mathrm{B}_{1}$.

Table 2. Mesh size for the three reduced models

\begin{tabular}{|l|c|c|c|c|}
\hline & Model A & Model B & Model B $_{\mathbf{2}}$ & Model C \\
\hline Elements & 1.104 .669 & 869.370 & 1.482 .001 & 546.724 \\
\hline Nodes & 198.229 & 153.209 & 263.583 & 98.925 \\
\hline
\end{tabular}

Boundary conditions for the reduced models were the same as for the industrial entry-device, except for the lateral cylindrical boundary that was set as free slip. Regarding the model C, sinks and sources were located $5 \mathrm{~mm}$ above and bellow the tray, respectively.

\section{$3 \quad$ RESULTS}

\subsection{Shape coefficient $C$ for hole discharge modeling}

\subsubsection{Numerical simulation}

In order to reduce computational cost, only $15^{\circ}$ of the overall $360^{\circ}$ hole-plate geometry were modeled. Simulation was aimed to reproduce the discharge of liquid through the hole with an initial liquid level of $0.3 \mathrm{~m}$ without feedback.

Fig. 5 shows the evolution of the mass flow rate $\dot{m}$ and the liquid level height $h_{f}$ along the simulation. Note that $\dot{m}$ reduces almost linearly with time, while $h_{f}$ follows a second order-polynomial relation with time.

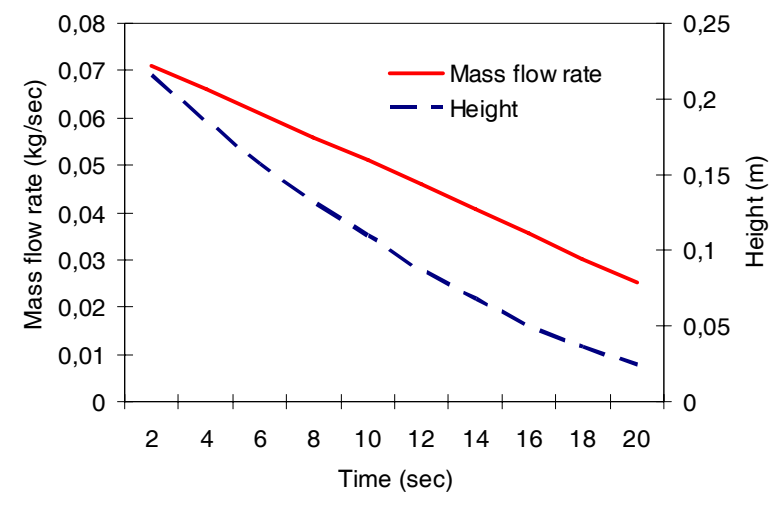

Figure 5. Mass flow rate $m$ and liquid level height $h_{f}$ during discharge 
By means of Equation 8 it was found the shape coefficient $C$ that better fits the CFD results is 0.77 . Fig. 6 shows the liquid mass flow rate in function of the hydrostatic pressure probed at $5 \mathrm{~mm}$ above the hole. Fig. 6 also shows the results obtained with Equation 8 for $\mathrm{C}=0.77$. As it can be noted, the results from CFD and Equation 8 are in fair agreement.

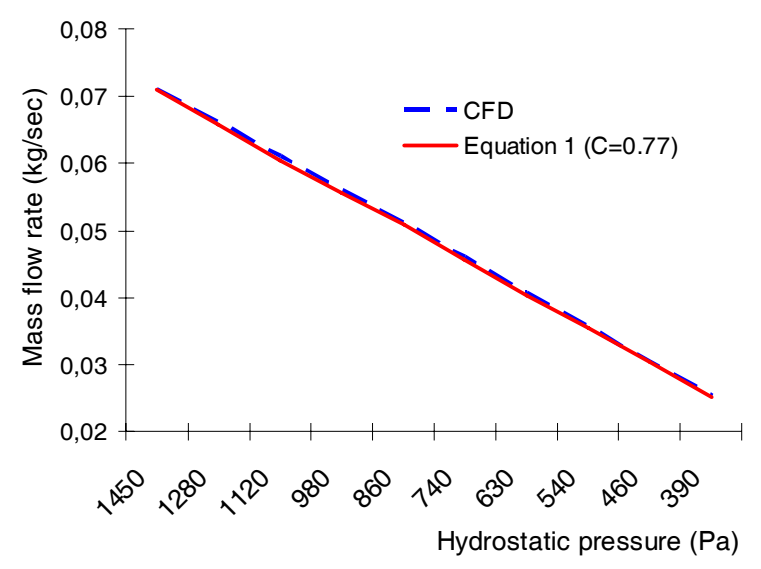

Figure 6. Mass flow rate as a function of the hydrostatic pressure probed at $5 \mathrm{~mm}$ above the hole

\subsubsection{Experimental test}

Experiment tests were fairly different from numerical ones in two aspects: first they were carried out with an air-water system (at room conditions); second the mass flow rate measurements were performed at constant water level. It is rather different from the numerical test in which fluid properties corresponded to hydrogen and $\mathrm{C}_{4}$ and the regime was non steady because the liquid level was not constant.

The average coefficient $C$ from experimental tests was 0.73 that is $5.2 \%$ less than the obtained from the numerical test. The explained differences between the test methodologies could justify these discrepancies. During experimental tests it was observed that the flow rate through the hole was strongly influenced by the turbulence around the hole, produced by the feedback from the top (inlet feedback was located approximately at $350 \mathrm{~mm}$ above the hole). At high liquid levels this feedback produced negligible disturbances and agitation of the liquid column near the hole, but at low liquid levels (less than $100 \mathrm{~mm}$ ) the discharge flow was significantly increased, leading to coefficient $C$ to overcome the value of 0.8 . Of course, this effect could not be observed for the numerical simulation since feedback was not taken into account. 


\subsection{Reduced tray models}

Fig. 7 displays the liquid volume fraction at a vertical mean cut plane for the three models. In all cases the global mass balance between the inlet and the outlet boundaries was reached for both phases. Note the discrepancies between the results of the model A (thickness perforated-plate) and the model B (nonthickness perforated-plate). For all models the initial liquid level was the same $(120 \mathrm{~mm})$, but the equilibrium level for the model B was scarcely lower than the one reached for the others. This behavior is expected due to the fact that the flow discharge coefficient $C$ for a non-thickness-plane hole is higher than for a thickness-plate hole with a thickness similar to the hole diameter $(0.8 \mathrm{~mm}$ in this case).

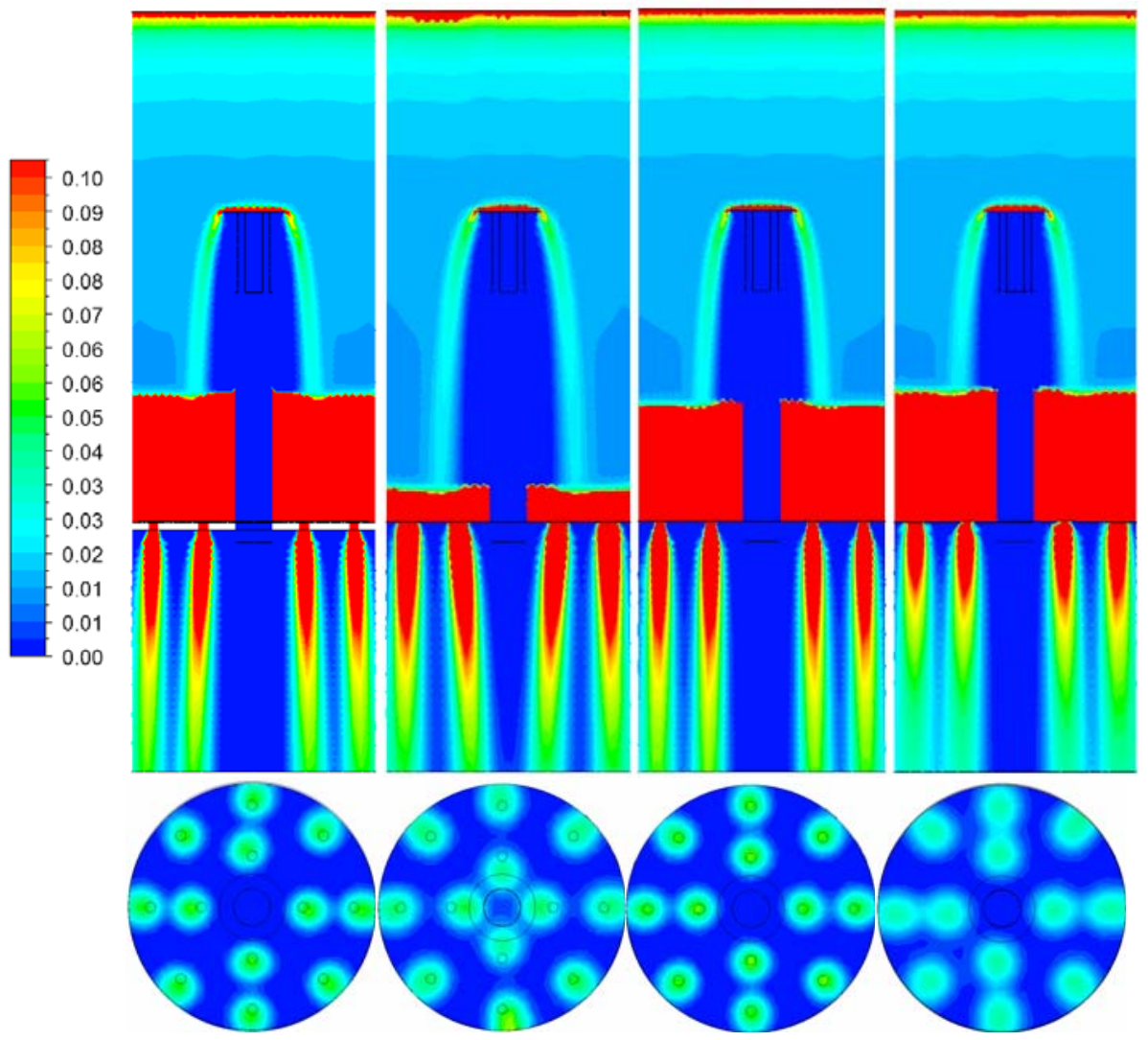

Figure 7. Liquid volume fraction. From left to right: model $\mathrm{A}$, model $\mathrm{B}_{1}$, model $\mathrm{B}_{2}$ and model $\mathrm{C}$

Fig. 8 and 9 show the vertical velocity for the liquid and the gas phases, respectively. Comparing the models $\mathrm{A}$ and $\mathrm{C}$ the liquid velocity pattern is fairly similar above the plate, although below it, the result from model C seems to be a little bit more dissipative. 


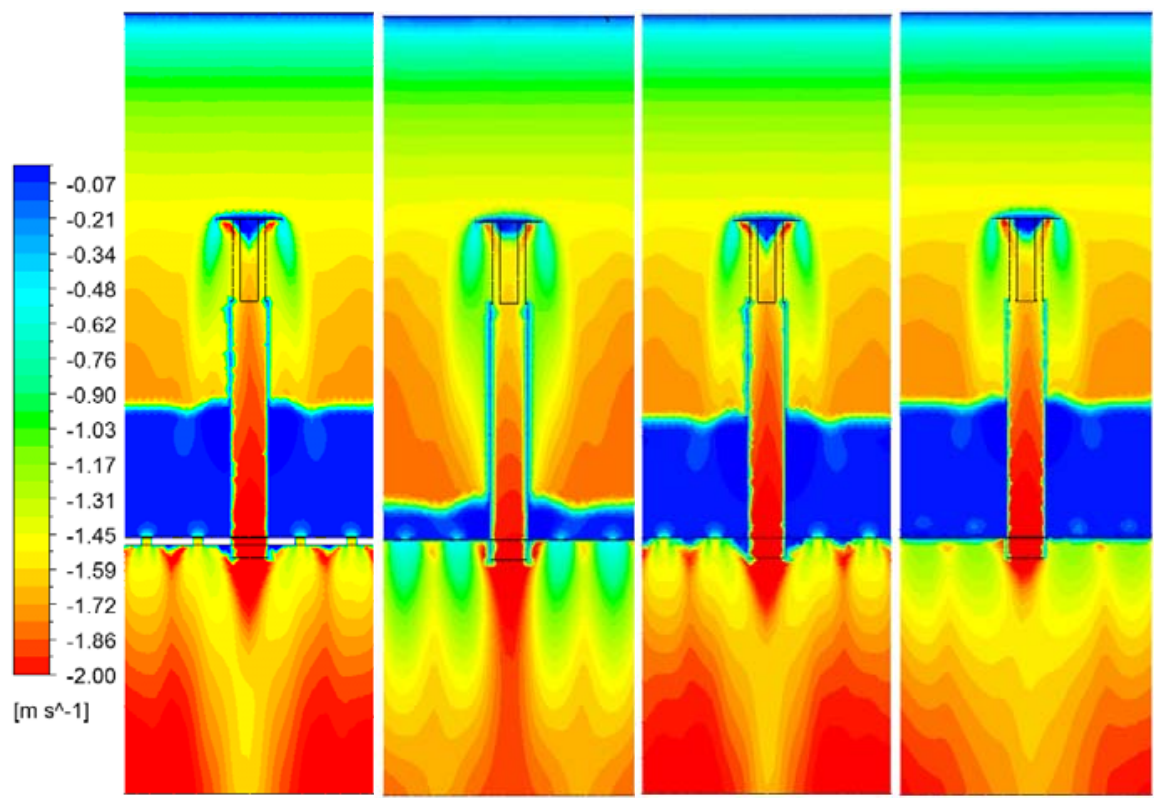

Figure 8. Vertical velocity for liquid phase. From left to right: model A, model $\mathrm{B}_{1}$, model $\mathrm{B}_{2}$ and model C

Since the gas mass flow rate is very small, gas motion is mainly promoted by liquid drag. As it can be seen in Fig. 9, the gas goes down dragged by the liquid and significant gas recirculation is found below the central chimney.

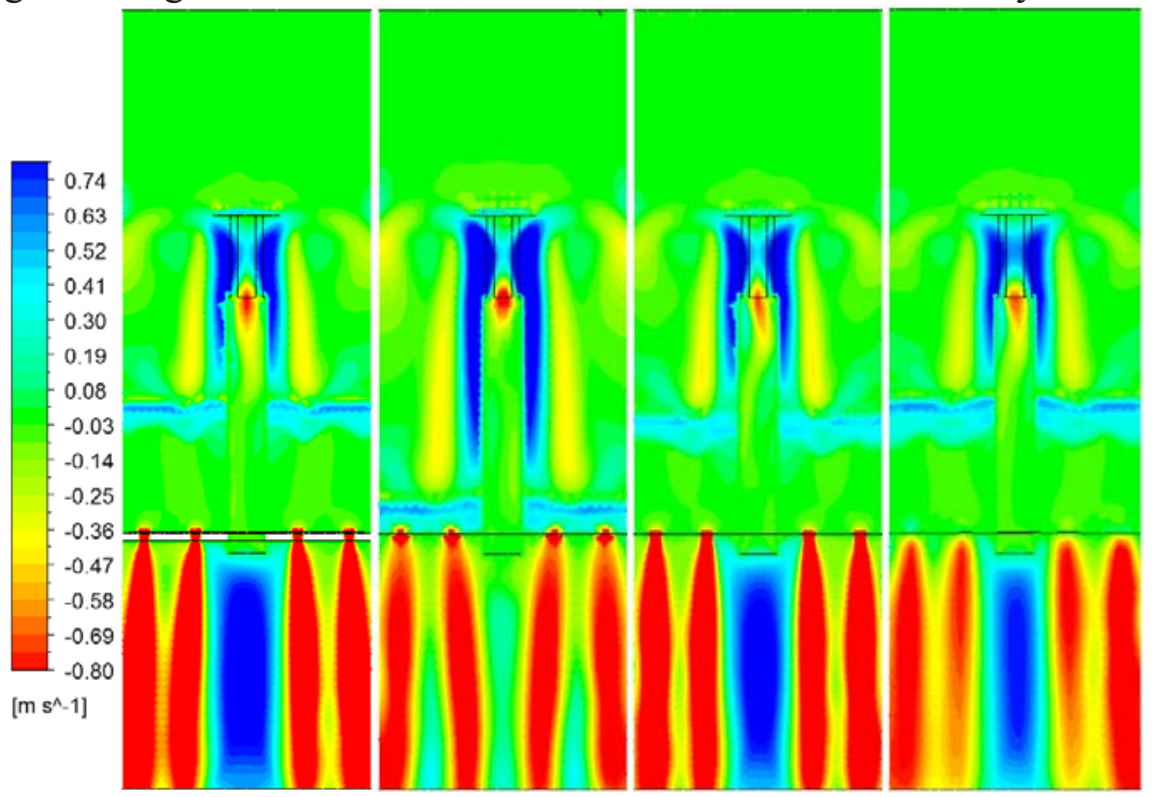

Figure 9. Vertical velocity for gas phase. From left to right: model A, model $\mathrm{B}_{1}$, model $\mathrm{B}_{2}$ and model C 
Fig. 7, 8 and 9 allow to conclude that the use of sinks and sources is a suitable option to model the behavior of small holes that are notably smaller than the whole domain characteristic length.

Regarding the convergence of the global mass balance, it was extremely slow for the gas phase. That may be related to the fact that the liquid mass flow rate was more than 1500 times higher than the gas one. As it is well known the multiphase two-fluid model is not mathematically well posed for problems involving large differences in density between phases or where a phase has a volume fraction close to zero (typically in the interface between phases) or high slip velocities between phases (Zanotti et al., 2007). So, for the system analyzed here (the mass flow rate of one fluid is quite smaller than the others), a double precision solver and large CPU time were necessary to get acceptable errors in the global mass balance. regarding model B, approximately 1.800 time steps were required to reduce the relative error of the global gas-mass balance below $10 \%$, while for models A and C approximately 10.000 time steps were solved to reduce the error below to $5 \%$.

The convergence of the gas phase was slower than that of the liquid as it is clearly shown in Table 3. In this table the global mass balance and the relative errors of model $\mathrm{C}$ for both phases at three simulation times are included. As noted, after $43.75 \mathrm{sec}$. (8750 time steps) the global liquid mass balance error was less than $0.5 \%$, but additional $8 \mathrm{sec}$. have to be simulated to reduce the error below to $0.14 \%$ (around 38 hours CPU time were required using 10 processors to compute the $8 \mathrm{sec}$.). On the other hand, the error corresponding to the gas phase is still high at $43.75 \mathrm{sec}$. but it is notoriously reduced at $51.75 \mathrm{sec}$. Although the high error on gas phase balance at $20 \mathrm{sec}$. and $43.75 \mathrm{sec}$, the liquid volume fraction result quite similar for the three times, concluding that high errors in the global mass balance of the gas phase have negligible effects over the liquid behavior. Moreover, the gas vertical velocity pattern also seems to be quite at the three times.

Table 3. Mass flow rate at inlet and outlet and global mass balance error at three simulation times for model $\mathrm{C}$

\begin{tabular}{|l|l|l|l|c|}
\hline \multirow{2}{*}{$\begin{array}{l}\text { Time } \\
(\mathrm{sec})\end{array}$} & & \multicolumn{2}{|c|}{ Mass flow rate $(\mathrm{kg} / \mathrm{sec})$} & \multirow{2}{*}{$\begin{array}{c}\text { Error } \\
\%\end{array}$} \\
\cline { 3 - 4 } & & \multicolumn{1}{|c|}{ Inlet } & Outlet & \\
\hline \multirow{2}{*}{20.0} & Liquid & $6.1014 \times 10^{-1}$ & $5.8233 \times 10^{-1}$ & 4.6 \\
\cline { 2 - 4 } & Gas & $4.0353 \times 10^{-4}$ & $1.0122 \times 10^{-3}$ & 151 \\
\hline \multirow{2}{*}{43.75} & Liquid & $6.1014 \times 10^{-1}$ & $6.0745 \times 10^{-1}$ & 0.44 \\
\cline { 2 - 4 } & Gas & $4.0353 \times 10^{-4}$ & $4.6373 \times 10^{-4}$ & 14.9 \\
\hline \multirow{2}{*}{51.75} & Liquid & $6.1014 \times 10^{-1}$ & $6.0929 \times 10^{-1}$ & 0.14 \\
\cline { 2 - 4 } & Gas & $4.0353 \times 10^{-4}$ & $4.2211 \times 10^{-4}$ & 4.61 \\
\hline
\end{tabular}


In summary, for this problem reducing the error of the global mass balance of the gas phase may have no sense because only the liquid phase plays a key role on fluid dynamics. Gas flow convergence is extremely hard to achieve and it seems not to affect liquid behavior, so the convergence criteria or the number of iterations (in each time step) for the mass and momentum equations of the gas phase can be reduced to a minimum in order to minimize the computational costs.

\subsection{Industrial TBR}

The average liquid level $h_{a v}$ for the steady state operation was obtained using the following equation:

$h_{a v}=\frac{1}{2 \vec{g} \rho^{2}}\left(\frac{\dot{m_{\text {nom }}}}{N_{h o} \cdot C \cdot A}\right)^{2}$

where $\overrightarrow{m_{\text {nom }}}$ is the liquid mass flow rate and $N_{\text {ho }}$ is the number of tray holes ( $N_{\text {ho }}$ $=68$ ). For $C=0.77$ (from CFD) $h_{a v}$ is approximately $112 \mathrm{~mm}$, being quite less than the spilling limit of $230 \mathrm{~mm}$ imposed by the gas chimney slots.

Fig. 10 shows the volume fraction (on the left) and velocity (on the center) of the liquid along with the gas velocity (on the right) at a mean cross sectional plane. In the figures variables were clipped only drawing the values included within the maximum and the minimum of the range. Regarding gas and liquid velocity figures, velocity only was drawn when the volume fraction of the corresponding phase was upper than 0.01. Note that even though the inlet distributor sprays liquid over chimneys, it only flows through the tray holes (modelled as sinks and sources). Sloshing is not strong, so the liquid level is almost constant excepting where jets directly impact the liquid free surface. 


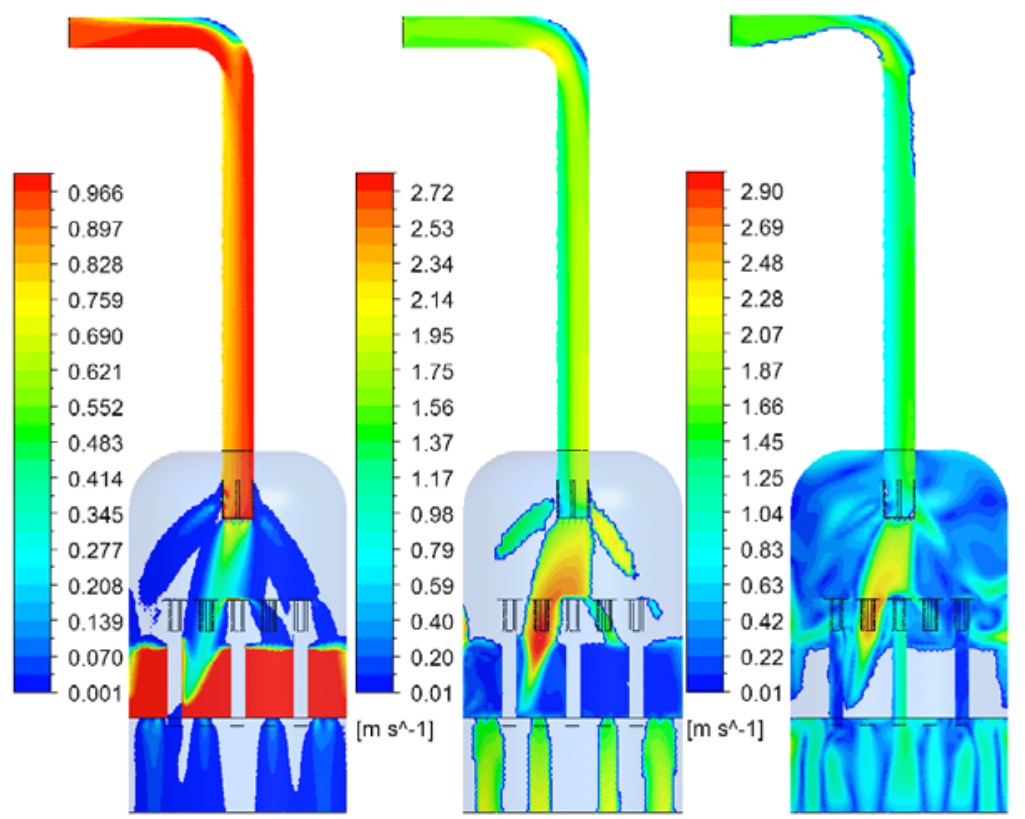

Figure 10. Results at the mean cross sectional plane. Left: liquid volume fraction. Center: liquid velocity. Right: gas velocity

Fig. 11 shows the time-average (last 1000 time steps) of the liquid mass flow rate through each one of the 68 holes. Holes were grouped dividing the perforated-plate in quarters (see Fig. 11 on the upper right side). Note that the mass flow rates range between $4.977 \times 10^{-2}$ and $5.202 \times 10^{-2} \mathrm{~kg} / \mathrm{sec}$., being the average of all holes equal to $5.0695 \times 10^{-2} \mathrm{~kg} / \mathrm{sec}$. (represented by a dashed line) and the standard deviation only $5.1272 \times 10^{-2} \mathrm{~kg} / \mathrm{sec}$. This points out that the mass flow rate of each hole differs in less than $2 \%$ with respect to the average.

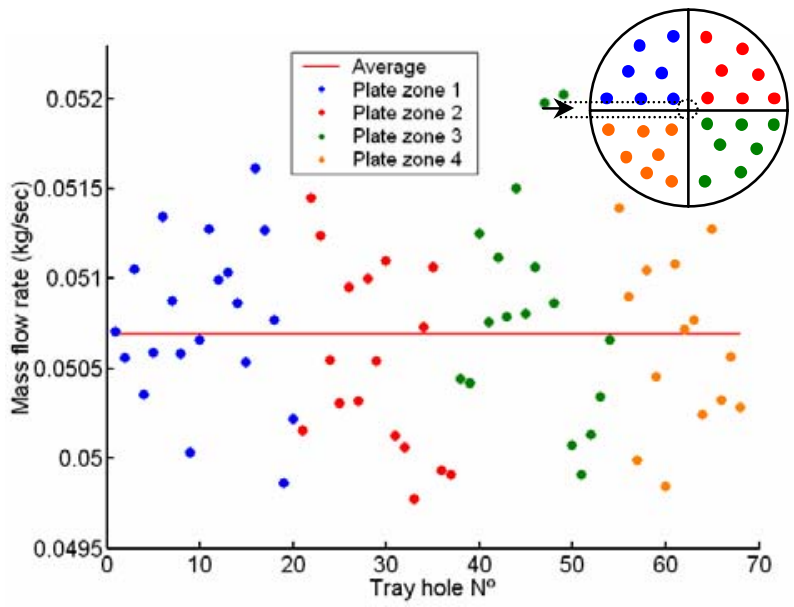

Figure 11. Time-average mass flow rate through the tray holes 
Fig. 12 shows the liquid volume fraction at two distances below the tray; the left picture corresponds to a cross sectional plane at the middle between the tray and the ceramic-ball bed (outlet of the computational domain) and the right picture corresponds to a plane placed at the ceramic-ball bed height. Note that, wetting is poor near the reactor wall and directly below chimneys. As expected the liquid falls following almost vertical trajectories. That is due to the liquid velocity through holes is not enough to cause flashing or spraying and also that the low gas flow rate flowing through chimneys does not disturb the liquid flow.
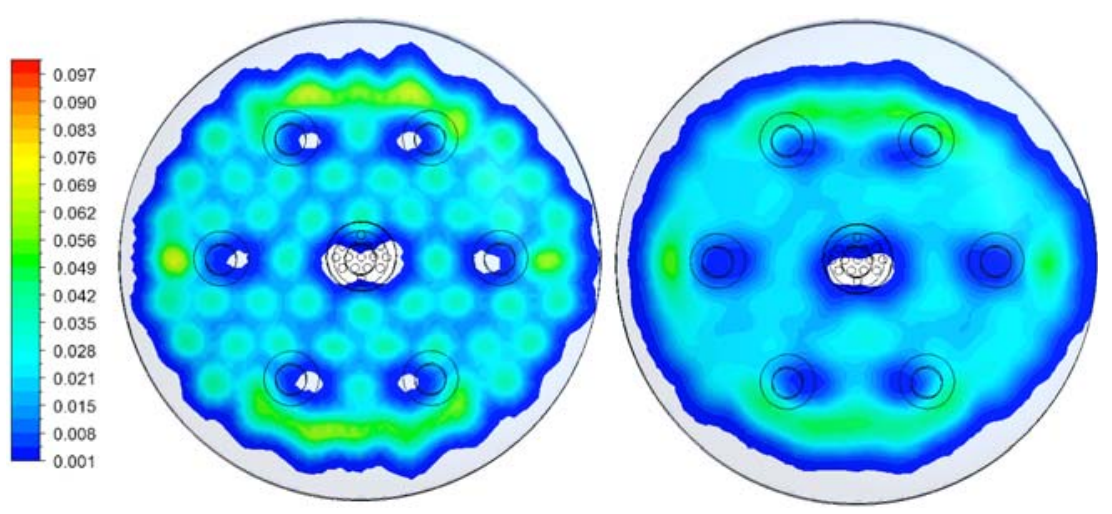

Figure 12. Liquid volume fraction. Left: at a cross sectional plane at $125 \mathrm{~mm}$ above the tray. Right: at the top of the ceramic-ball bed (at $250 \mathrm{~mm}$ above the tray)

Since the gas flow has negligible effects over liquid phase and the last can be represented by Equation 8, it is easy to carry out simple predictions of the tray distributor behavior under different operating conditions and plugging situations if some holes are obstructed. Fig. 13 shows the area fraction (at the top of the ceramic-ball bed) that is efficiently wetted for different wetting criteria. For example, the optimal criterion (100\%) means that the ceramic-ball bed is wetted with a homogeneous liquid flux $\left(\varnothing_{h}\right)$ equal to $\varnothing_{h}=\dot{m}_{T} / A_{T}$, being $\dot{m}_{T}$ the total liquid mass flow rate $\left(3.4575 \mathrm{~kg} / \mathrm{sec}\right.$.) and $A_{T}$ the area at the top of the bed $\left(0.255 \mathrm{~m}^{2}\right)$. Fig. 13 shows that around half of the $A_{T}$ is wetted with a liquid flux equal or more than $\varnothing_{h}$, while around $65 \%$ of $A_{T}$ receives at less half of $\varnothing_{h}$. The curve corresponding to the TBR design operating conditions is also included in Fig. 13. For this case, the mass flow rates of both phases are increased approximately $25 \%$ with respect to the current operating conditions. Note that curves are essentially the same for both operating conditions, indicating that the current operating conditions seem not to be far from the design operation range. 


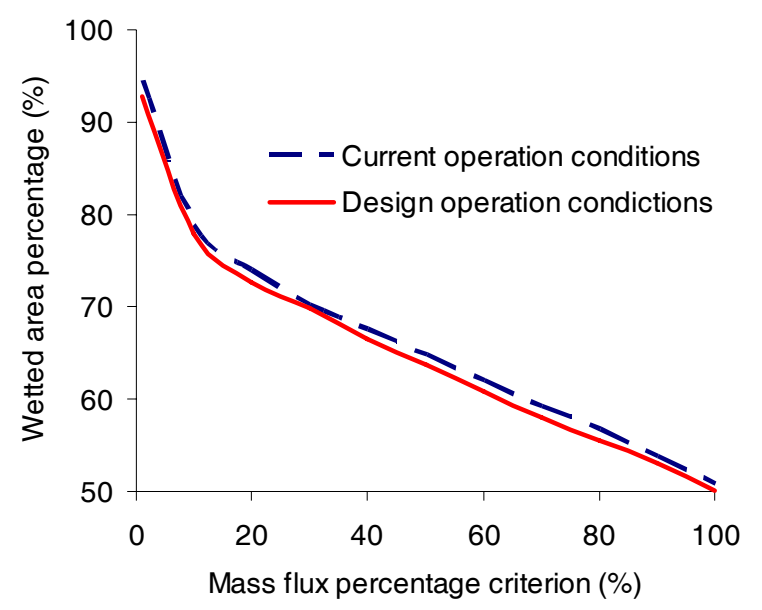

Figure 13. Wetted area percentage as a function of a cut criterion based on a percentage of average liquid mass flux

Fig. 14 shows the mass flow rate of both phases through each one of the 7 tray chimneys. As it is noted, the gas flows down mainly through chimneys 3 and 4, while a significant amount of gas flows up through the central chimney. The gas recirculation flow is around 30 times of the net gas flow $\left(4.0353 \times 10^{-4}\right.$ $\mathrm{kg} / \mathrm{sec}$.). Due to the low inlet gas flow rate, the liquid jets that impact over the top of some chimneys induce local pressure drops around those chimneys inducing gas ascension. Although these results are unexpected because the tray was not designed to promote gas recirculation, this effect enhances the mixing between phases.

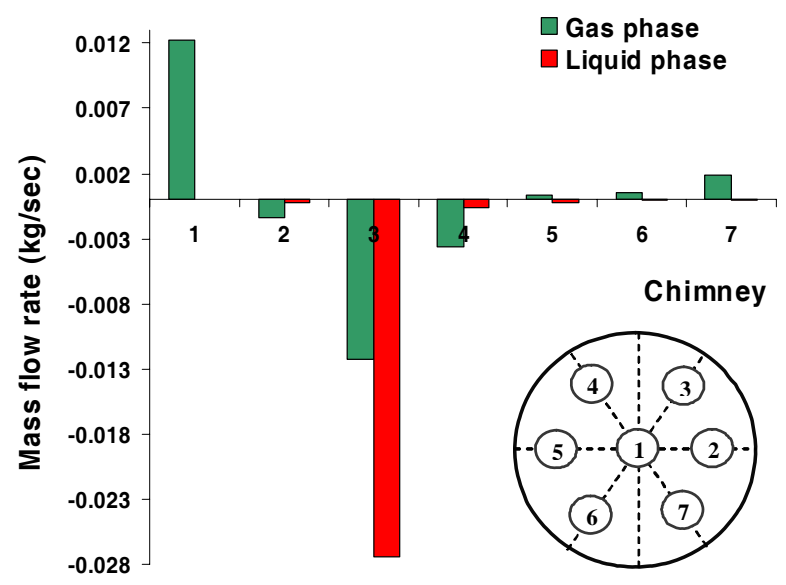

Figure 14. Mass flow rate of the liquid and gas phases through the chimneys 


\subsection{Some possible scenarios that could explain the low efficiency of the TBR}

From literature, it is clear that perforated-plate trays have lower efficiency than other tray technologies like chimney trays, bubble cap trays or vapor lift trays (VLT). An important cause of low efficiency in perforated-plate trays is due to small tray unevenness that can originate non homogeneous liquid level, causing that some holes discharge more liquid than others. But the major disadvantage of perforated-plate trays is the high tendency to fouling and plugging due to the obstruction of holes with coke, corrosion products or other debris carried into the reactor by the feed. (Alvarez et al., 2007; Maiti et al., 2007). From Equation 9 it is possible to estimate the liquid level $h_{a v}$ as a function of the amount of obstructed holes. That is showed in Fig. 15 along with maximum liquid level (defined by the chimney slots). Note that at less 20 holes have to be obstructed before liquid starts flow through chimneys.

From simulation results it was found that liquid trajectories are nearly below the holes. So, it is very likely that a significant fraction of the ceramic-ball bed would be poorly wetted if some holes around the chimneys are plugged.

As reported in literature, another important source of non-uniform liquid distribution is due to tray unevenness caused during the installation or maintenance operation, it being more significant while larger is the tray diameter. A rough estimation of the liquid unevenness in function of the tray inclination angle can be done by geometric considerations, that leading for this TBR to a maximum and average liquid unevenness of 10 and $2.5 \mathrm{~mm} /$ degree, respectively. Then, from Equation 8 the difference on the mass flow rate difference for two holes placed below the minimum and the maximum liquid level will be $5 \%$ per each unevenness degree.

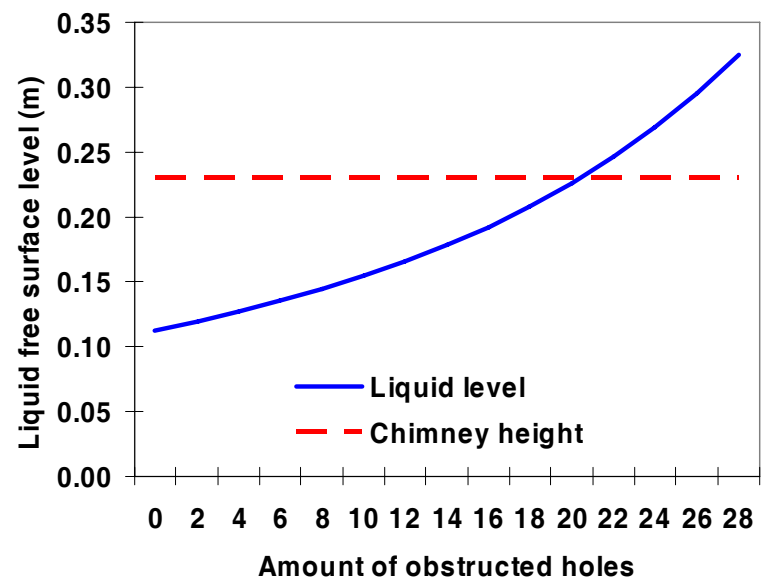

Figure 15. Liquid level height as a function of the amount of obstructed holes 
Another possible cause of bad liquid distribution could be due to liquid canalization at the reactor walls, thermocouples or structural supports. However, for this reactor, thermocouples are located cross transversal to the reactor and there are not structural supports at the catalyst bed. Besides, from Fig. 12 the liquid volume fraction seems not be high near the reactor walls.

\subsection{Effect of the ceramic-ball bed on wetting efficiency}

The ceramic-ball bed over the catalyst bed has the function of enhance the liquid distribution and the mixture of reactants. Alvarez et al. (2007) suggested a simple equation to quantify its effect by estimating the radial diffusion of the liquid inside the ball bed:

$$
l_{d}=\sqrt{z \cdot k_{H} \sqrt{d_{p}}}
$$

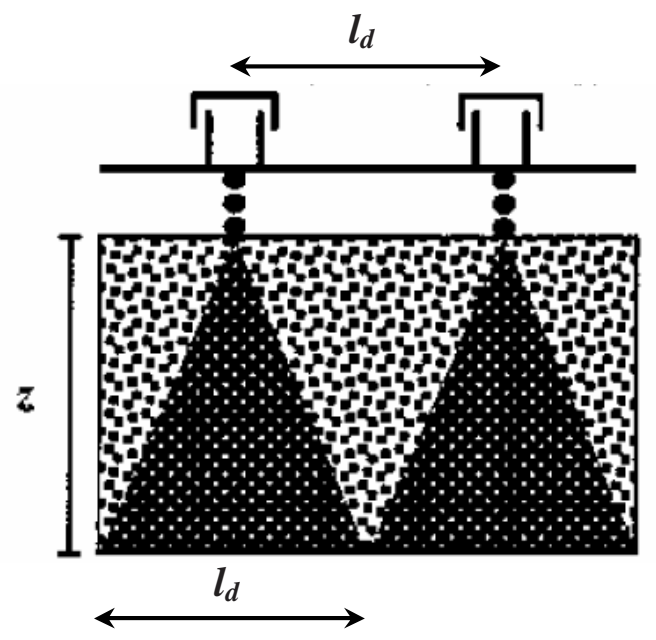

where $l_{d}$ is the diameter of the wetting cone, $z$ is the bed height $(150 \mathrm{~mm}), d_{p}$ is the diameter of the balls and $k_{H}$ is a constant parameter. Note that the radial diffusion is proportional to $k_{H}$, which must be hold below 4 to guarantee a homogeneous distribution. Due to the liquid falls almost vertically from the tray, it is easy to estimate the amount of wetting cones that wets each point of the top of the catalyst bed. Fig. 16 shows it for two $k_{H}, 2$ and 4 . 

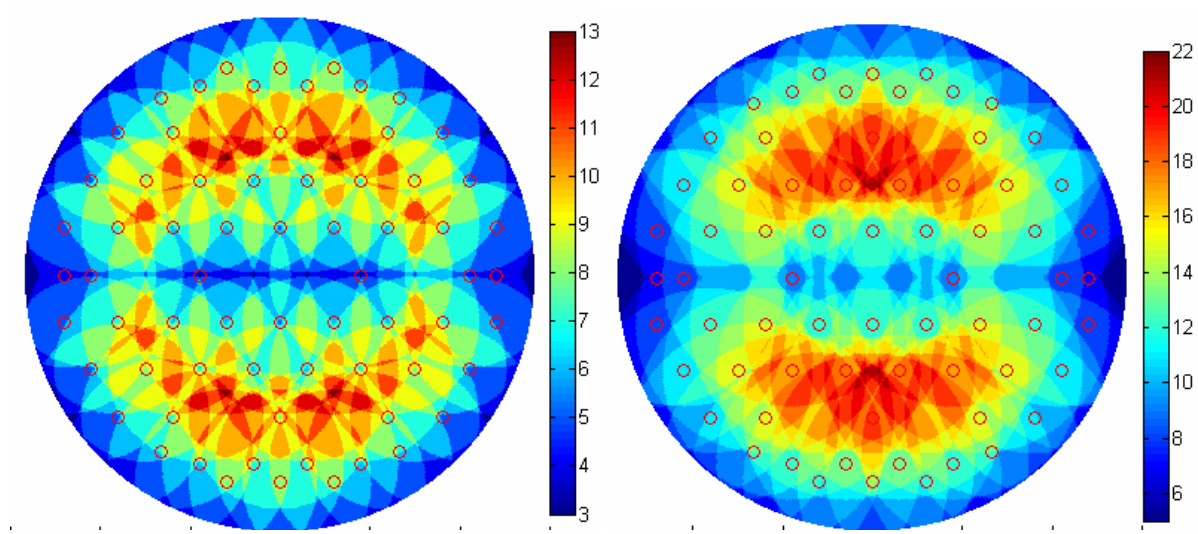

Figure 16. Amount of wetting cones (holes) that wets each point of the top of the catalyst bed. Left: $k_{H}=2$. Right: $k_{H}=4$

\subsection{Tray geometry modifications}

More efficient distribution trays are currently employed in trickled bed reactors, but most of these technologies need high gas flow rates to work. For example caps or lift tubes are basically two coaxial vertical tubes where the liquid phase is dragged upwards through the external tube driven by the gas phase, both falling together through the central tube. Another technology is the chimneys that are composed of a vertical tube with a hat at the top and small holes at different heights from the plate. In this case the gas flow downwards from the opened top while the liquid enters to the tube through the holes. This kind of trays reduces fouling, although they are quite larger than the holes of the perforated-plate trays so the amount of drip points is sensibly reduced.

CFD results point out that the non-homogeneous wetting could explain the low reactor efficiency. Moreover, the influence of gas flow over the liquid behavior can be neglected. Then it is possible to propose two geometric modifications in order to improve wetting; first, reducing the amount of chimneys to only one (the central chimney), thus adding more liquid drip points. Moreover with only one chimney the downward mean velocity of the gas will be around $0.22 \mathrm{~m} / \mathrm{sec}$. and gas recirculation will disappear. Second, replacing the holes by short risers of around $50 \mathrm{~mm}$ height, in order to reduce the vulnerability to plugging of this kind of trays.

Fig. 17 shows the amount of wetting cones (holes) that will wet each point of the catalyst bed if 8 new drips are added ( 6 at the location of the 6 chimneys removed and 2 close to the central chimney). 


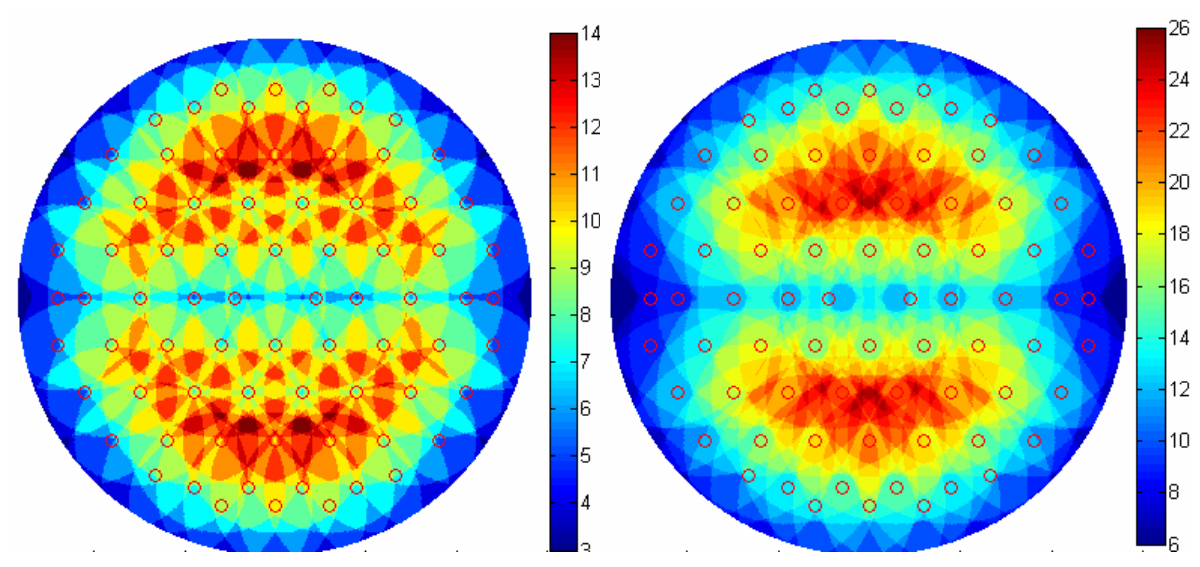

Figure 17. Amount of wetting cones (holes) that wets each point of the catalyst bed when 8 drips are added. Left: $k_{H}=2$. Right: $k_{H}=4$

For this new tray the average of wetting cones is increased from 7.3 to 8.7 for $k_{H}=2$ and from 12.9 to 15.5 for $k_{H}=4$. That is reflected by Fig. 18 where the average and the standard deviation of the amount of wetting cones (holes) that impinge each point of the catalyst bed are drawn in function of $k_{H}$ for the current and the modified trays.

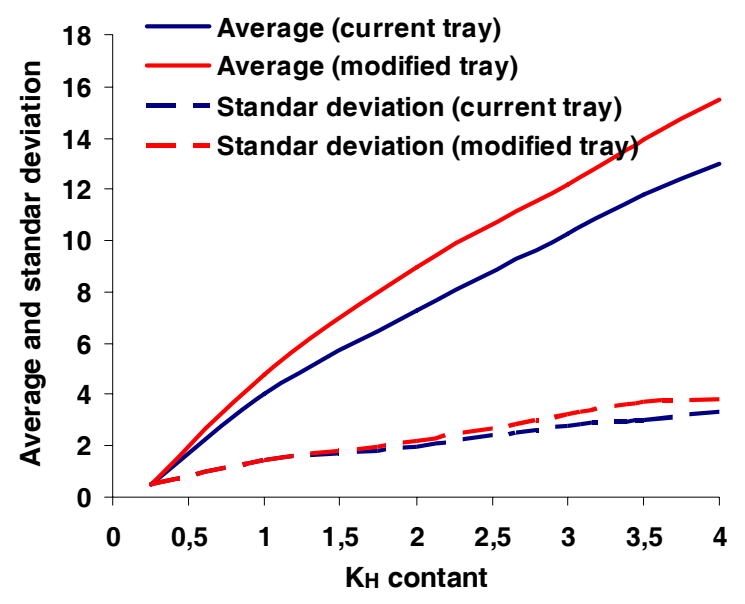

Figure 18. Average and standard deviation of the amount of drip points that wets each point of the catalyst bed as a function of the $k_{H}$

\section{CONCLUSIONS}

A two-phase turbulent flow in the entry device of an industrial TBR was simulated by CFD. The wetting efficiency and gas and liquid flow patterns were studied in deep, which lead to the following conclusions: 
$a$ - the use of sinks and sources is a suitable option for modeling the tray-holes $b$ - in systems with very low gas flow rate, the liquid flow behavior is not affected by the correct prediction of the gas phase flow, so a high computational cost can be saved by set a high convergence tolerance for solving the mass and momentum equations for the gas phase (relaxation of the convergence criteria for gas phase)

$c$ - the shape coefficient $C$ that characterize the geometry of the tray holes was obtained by CFD for the reactor conditions and by experimental tests with water-air under room conditions, leading to relatively good agreement

$d$ - the liquid level over the tray is quite homogeneous, so all holes show a similar flow. The liquid fall almost vertically and the gas has a negligible effect on liquid behavior

$e$ - although the ceramic-ball bed radially distributes the liquid wetting almost all of the top of the catalyst bed, there are zones where the liquid concentration is 3 or 4 times greater than others

$f$ - two simple constructive modifications were proposed; reducing the amount of gas chimneys to only one, adding new drips, and changing the current perforated-plate holes by short risers in order to reduce the vulnerability to plugging of the tray.

\section{ACKNOWLEDGEMENTS}

Authors want to thanks to CONICET (grant 5271/05), ANPCyT (grant PICT 01141/2007), UNL (grant CAI+D 2009 Tipo II PI-65-333). Also they are gratefully to CTA, YPF S.A. to proportionate the industrial data and the plant experience required to carry out this research.

\section{REFERENCES}

Alvarez A., Ramírez S., Ancheyta J. and Rodríguez L., "Key Role of Reactor Internals in Hydroprocessing of Oil Fractions", American Chemical Society, 2007.

Atta A., Roy S. and Nigam K., "Investigation of liquid maldistribution in trickle-bed reactors using porous media concept in CFD", Chem. Eng. Science, 2007, 62, 7033-7044.

Bingham E. and Nelson D., "Practical advances in petroleum processing", chapter 13: Advanced reactor internals for hydroprocessing units,2006, Springer New York. 
Dally, J. W., W. F. Riley, and K. G. McConnell, "Instrumentation for Engineering Measurements", 1993, John Wiley and Sons, Inc. 2ed.

Drew D., and Passman S., "Theory of Multicomponent Flow”, 1998, Springer, New-York.

Gunjal P., Kashid M., Ranade V. and Chaudhari R., "Hydrodynamics of tricklebed reactors: experiments and CFD modeling”, Ind. Eng. Chem. Res., 2005, 44, 6278-6294.

Harter I, Boyer C., Raynal L., Ferschneider G. and Gauthier T., "Flow distribution studies applied to deep hydro-desulfurization", Ind. Eng. Chem. Res., 2001, 40, 5262-5267.

Kundu A., Saroha A. and Nigam K., "Liquid distribution studies in trickle-bed reactors", Chem. Eng. Science, 2001, 56, 5963-5967.

Maiti R. and Nigam K., "Gas-liquid distributors for trickle bed reactors: a review”, American Chem. Society, 2007, 6164-6182.

Mendez C., Nigro N., and Cardona A., "Non-drag forces influence in numerical simulations of metallurgical ladles", J. of Materials Processing Tech., 2005, 160, 296-305.

Lopes R. and Quinta-Ferreira R., "Three-dimensional numerical simulation of pressure drop and liquid holdup for high-pressure trickle-bed reactor", Chem. Eng. J., 2008, 145, 112-120.

Perry R. and Chilton C., "Chemical Engineers' Handbook”, 6 ed., 1984 McGraw-Hill Co.

Ranade V., "Computational flow modeling for chemical reactor engineering", 2002, Academic Press.

Ramajo D, Raviculé M., Horowitz G., Storti M., Nigro N., "CFD Analysis of a Polibutene Reactor to Diagnose Causes of Polymer Adhesion at Inner Walls", 2008, Latin American Applied Research, 38, 4, 351-359.

Ramajo D, Raviculé M., Monsalvo M., Marquez Damian S., Storti M., Nigro N., "CFD Study of Flow Distribution and Wetting Efficiency of the Perforated 
Tray Distributor of a Trickle Bed Reactor”, 2009, ENIEF 2009,1641-1660.

Storti M, Nigro N. and Paz R., "PETSc-FEM a general purpose, parallel, multyphysics fem program", 2002, International Center of Computational Method in Engineering (CIMEC), Argentina http://www.cimec.org.ar/petscfem.

Sonzogni, V., Yommi, A., Nigro, N., and Storti, M., "A parallel finite element program on a Beowulf Cluster", Advances in Engineering Software, 2002, 33, 427-443.

Zanotti A., Méndez C, Nigro N. and Storti M., "A Preconditioning Mass Matrix to Avoid the Ill-Posed Two-Fluid Model", ASME Journal of Applied Mechanics, 2007, 74, 4, 732-740. 